\title{
Taxonomy of the order Bunyavirales: update 2019
}

\author{
Abulikemu Abudurexiti ${ }^{1}$. Scott Adkins ${ }^{2}$ - Daniela Alioto ${ }^{3}$ - Sergey V. Alkhovsky ${ }^{4}$ (D) Tatjana Avšič-Županc ${ }^{5}$.

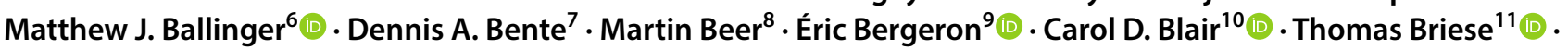 \\ Michael J. Buchmeier ${ }^{12}$ - Felicity J. Burt ${ }^{13}(\mathbb{0})$. Charles H. Calisher ${ }^{10}$. Chénchén Cháng ${ }^{14} \cdot$ Rémi N. Charrel $^{15}{ }^{(1)}$. \\ II Ryong Choi ${ }^{16} \cdot$ J. Christopher S. Clegg ${ }^{17}$. Juan Carlos de la Torre ${ }^{18}\left({ }^{\circ} \cdot\right.$ Xavier de Lamballerie $^{15} \cdot$ Fẽi Dèng $^{19}$ (1) \\ Francesco Di Serio ${ }^{20}$ (1) Michele Digiaro ${ }^{21}$. Michael A. Drebot ${ }^{22} \cdot$ Xiǎoméi Duàn $^{14} \cdot$ Hideki Ebihara ${ }^{23}$ (1) \\ Toufic Elbeaino $^{21}$ - Koray Ergünay ${ }^{24}$ (1) . Charles F. Fulhorst ${ }^{7}$. Aura R. Garrison ${ }^{25}$ (1) - George Fú Gāo ${ }^{26}$. \\ Jean-Paul J. Gonzalez ${ }^{27}$ - Martin H. Groschup ${ }^{28}$ (1) Stephan Günther ${ }^{29}$ (1) Anne-Lise Haenni ${ }^{30} \cdot$ Roy A. Hall $^{31}$.

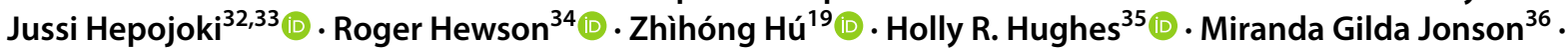 \\ Sandra Junglen ${ }^{37,38}$. Boris Klempa ${ }^{39}$ (D) Jonas Klingström ${ }^{40}$. Chūn Kòu ${ }^{14}$. Lies Laenen ${ }^{41,42}$ (D) Amy J. Lambert ${ }^{35}$ (D)

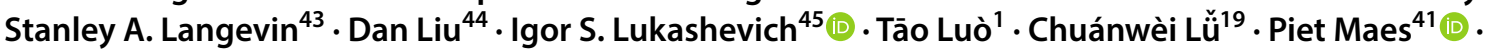 \\ William Marciel de Souza ${ }^{46}$ (1) Marco Marklewitz ${ }^{37,38}$ - . Giovanni P. Martelli ${ }^{47} \cdot$ Keita Matsuno ${ }^{48,49}$ (1) \\ Nicole Mielke-Ehret ${ }^{50} \cdot$ Maria Minutolo $^{3}$ (D) Ali Mirazimi ${ }^{51} \cdot$ Abulimiti Moming $^{14}$. Hans-Peter Mühlbach ${ }^{50}$. \\ Rayapati Naidu ${ }^{52}$. Beatriz Navarro ${ }^{20}$. Márcio Roberto Teixeira Nunes ${ }^{53}$. $\cdot$ Gustavo Palacios ${ }^{25}$. \\ Anna Papa ${ }^{54}$. Alex Pauvolid-Corrêa ${ }^{55}$. Janusz T. Pawęska ${ }^{56,57}$ - Jié Qiáo ${ }^{19}$. Sheli R. Radoshitzky ${ }^{25}$ (1). \\ Renato O. Resende ${ }^{58}$ (1) Víctor Romanowski ${ }^{59} \cdot$ Amadou Alpha Sall ${ }^{60} \cdot$ Maria S. Salvato ${ }^{61}\left(\right.$ (1) $\cdot$ Takahide Sasaya $^{62}(1)$.

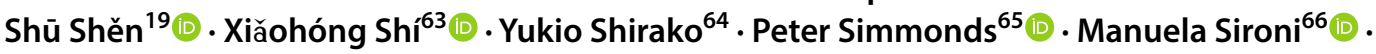

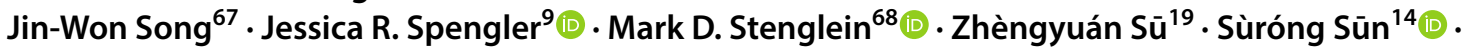 \\ Shuāng Táng ${ }^{19}$ - Massimo Turina ${ }^{69}$ - Bó Wáng ${ }^{19}$. Chéng Wáng ${ }^{1} \cdot$ Huálín Wáng ${ }^{19}$ - Jūn Wáng ${ }^{19}$. \\ Tàiyún Wèi $^{70} \cdot$ Anna E. Whitfield ${ }^{71}(1) \cdot F$. Murilo Zerbini ${ }^{72}(1)$. Jìngyuàn Zhāng ${ }^{14}$. Lèi Zhāng ${ }^{19}$. Yànfāng Zhāng ${ }^{19}$. \\ Yong-Zhen Zhang ${ }^{73,74}$. Yújiāng Zhāng ${ }^{1}$ Xueping Zhou ${ }^{75}$. Lìyǐng Zhü ${ }^{19}$. Jens H. Kuhn ${ }^{76}$
}

Received: 8 March 2019 / Accepted: 16 March 2019 / Published online: 7 May 2019

(c) This is a U.S. government work and its text is not subject to copyright protection in the United States; however, its text may be subject to foreign copyright protection 2019

Handling Editor: Sead Sabanadzovic.

Michael J. Buchmeier, Rémi N. Charrel, J. Christopher S. Clegg, Juan Carlos de la Torre, Jean-Paul J. Gonzalez, Stephan Günther, Jussi Hepojoki, Igor S. Lukashevich, Sheli R. Radoshitzky, Víctor Romanowski, Maria S. Salvato, Manuela Sironi, Mark D. Stenglein, Jens H. Kuhn: the members of the 2017-2020 International Committee on Taxonomy of Viruses (ICTV) Arenaviridae Study Group; Scott Adkins, Juan Carlos de la Torre, Sandra Junglen, Amy J. Lambert, Piet Maes, Gustavo Palacios, Takahide Sasaya, Yong-Zhen Zhang, Jens H. Kuhn: the members of the 2017-2020 ICTV Bunyavirales Study Group; Michele Digiaro, Toufic Elbeaino, Giovanni P. Martelli, Nicole MielkeEhret, Hans-Peter Mühlbach: the members of the 2017-2020 ICTV Fimoviridae Study Group; Charles H. Calisher, Charles F. Fulhorst, Boris Klempa, Jonas Klingström, Lies Laenen, Piet Maes, Jin-Won Song, Yong-Zhen Zhang: the members of the 2017-2020 ICTV Hantaviridae Study Group; Sergey V. Alkhovsky, Tatjana Avšič-Županc, Dennis A. Bente, Éric Bergeron, Felicity J. Burt, Michael A. Drebot, Koray Ergünay, Aura R. Garrison, Roger Hewson, Ali Mirazimi, Gustavo Palacios, Anna Papa, Janusz T. Pawęska, Amadou Alpha Sall, Jessica R. Spengler, Jens H. Kuhn: the members of the 2017-2020 ICTV Nairoviridae Study Group; Scott Adkins, Sergey V. Alkhovsky, Martin Beer, Carol D. Blair, Charles H. Calisher, Holly R. Hughes,
Amy J. Lambert, William Marciel de Souza, Marco Marklewitz, Márcio Roberto Teixeira Nunes, Xiăohóng Shí: the members of the 2017-2020 ICTV Peribunyaviridae Study Group; Matthew J. Ballinger, Roy A. Hall, Sandra Junglen, Stanley A. Langevin, Alex Pauvolid-Corrêa: the members of the 2017-2020 ICTV Phasmaviridae Study Group; Thomas Briese, Rémi N. Charrel, Xavier de Lamballerie, Hideki Ebihara, George Fú Gāo, Martin H. Groschup, Roberto Teixeira Nunes, Gustavo Palacios, Takahide Sasaya, Jin-Won Song: the members of the 2017-2020 ICTV Phenuiviridae Study Group; Il Ryong Choi, Anne-Lise Haenni, Miranda Gilda Jonson, Takahide Sasaya, Yukio Shirako, Tàiyún Wèi, Xueping Zhou: the members of the 2017-2020 ICTV Tenuivirus Study Group; Scott Adkins, Amy J. Lambert, Rayapati Naidu, Renato O. Resende, Massimo Turina, Anna E. Whitfield: the members of the 2017-2020 ICTV Tospovirus Study Group; Peter Simmonds: the 2017-2020 ICTV Chair of the Fungal and Protist Viruses Subcommittee; F. Murilo Zerbini: the 2017-2020 ICTV Chair of the Plant Viruses Subcommittee; and Jens H. Kuhn: the 2017-2020 ICTV Chair of the Animal dsRNA and ssRNA-Viruses Subcommittee.

Extended author information available on the last page of the article 


\section{Abstract}

In February 2019, following the annual taxon ratification vote, the order Bunyavirales was amended by creation of two new families, four new subfamilies, 11 new genera and 77 new species, merging of two species, and deletion of one species. This article presents the updated taxonomy of the order Bunyavirales now accepted by the International Committee on Taxonomy of Viruses (ICTV).

\section{Introduction}

The virus order Bunyavirales was established in 2017 to accommodate related viruses with segmented, linear, singlestranded, negative-sense or ambisense RNA genomes classified into nine families [19]. An amended/emended order description was published in early 2019 [20]. Here, we present the changes that were proposed via official ICTV taxonomic proposals that were accepted by the ICTV Executive Committee (EC) in February 2019. Therefore, these changes are now part of the official ICTV taxonomy.

\section{Taxonomic changes at the order rank}

The order was expanded by addition of two new families. Family Leishbuviridae was created to accommodate one new genus, Shilevirus, including one new species, Leptomonas shilevirus, for Leptomonas moramango leishbunyavirus (LEPMV) discovered in a trypanosomatid protist (Leptomonas moramango) [2]. Family Tospoviridae was recreated for the already established genus Tospovirus (now renamed Orthotospovirus; TaxoProp 2018.017M.A.v1. Bunyavirales_2fam5gen) and expanded by seven new species (TaxoProp 2018.025P.A.v1.Orthotospovirus_7sp):

- Bean necrotic mosaic orthotospovirus for bean necrotic mosaic virus (BeNMV) discovered in common beans (Phaseolus vulgaris) [8];

- Calla lily chlorotic spot orthotospovirus for calla lily chlorotic spot virus (CCSV) found in calla lilies (Zantedeschia sp.) [5, 18];

- Capsicum chlorosis orthotospovirus for capsicum chlorosis virus $(\mathrm{CaCV})$ found in capsicums, chillies, and tomatoes [16, 23];

- Chrysanthemum stem necrosis orthotospovirus for chrysanthemum stem necrosis virus (CSNV) infecting chrysanthemums [3, 10];

- Melon severe mosaic orthotospovirus for melon severe mosaic virus (MSMV) infecting cucurbit crops [6, 7];
- Melon yellow spot orthotospovirus for melon yellow spot virus (MYSV) found in netted melon (Cucumis melo) [15]; and

- Soybean vein necrosis orthotospovirus for soybean vein necrosis virus (SVNV) discovered in soybeans (Glycine $\max )$ [36].

A genus unassigned to any family, Coguvirus, was established to include species Citrus coguvirus for citrus concave gum-associated virus (CCGaV) found in citrus trees [26] (TaxoProp 2018.020P.A.v1.Coguvirus).

\section{Taxonomic changes at the family rank}

\section{Arenaviridae}

The family Arenaviridae was expanded by one genus, Antennavirus, to include two new species, Hairy antennavirus and Striated antennavirus, for Wēnlǐng frogfish arenavirus 2 (W1FV-2) and Wēnlǐng frogfish arenavirus 1 (W1FV-1), both found in striated frogfish (Antennarius striatus) [33] (TaxoProp 2018.005M.A.v1.Antennavirus).

\section{Cruliviridae}

No changes were made at the family rank.

\section{Fimoviridae}

No changes were made at the family rank.

\section{Hantaviridae}

The family (TaxoProp $2018.010 \mathrm{M}$.A.v2. Hantaviridae_4subfam) was reorganized into four subfamilies:

- subfamily Actantavirinae was created for the new genus Actinovirus to accommodate three novel species: Batfish actinovirus for Wēnlǐng minipizza batfish virus (WEMV) discovered in minipizza batfish (Halieutaea stellata); Goosefish actinovirus for Wēnlǐng yellow goosefish virus (WEYGV) found in yellow goosefish (Lophius litulon); and Spikefish actinovirus for Wēnlǐng red spikefish virus (WERSV) of red spikefish (Triacanthodes anomalus) [33];

- subfamily Agantavirinae was created for the new genus Agnathovirus to accommodate one new species, Hag- 
fish agnathovirus, for Wēnlı̌ng hagfish virus (WEHV) of inshore hagfish (Eptatretus burgeri) [33];

- subfamily Mammantavirinae was created to accommodate the established genera Loanvirus, Mobatvirus, and Orthohantavirus. Two new orthohantavirus species, Seewis orhtohantavirus and Tigray orthohantavirus, were created for Seewis virus (SWSV) of Eurasian common shrews (Sorex araneus) [34] and Tigray virus (TIGV) of Ethiopian white-footed mice (Stenocephalemys albipes) [12, 25], respectively; and

- subfamily Repantavirinae was created for the new genus Reptillovirus to accommodate one new species, Gecko reptillovirus, for Hăinán oriental leaf-toed gecko virus (HOLGV) discovered in oriental leaf-toed geckos (Hemidactylus bowringii) [33].

\section{Mypoviridae}

No changes were made at the family rank.

\section{Nairoviridae}

The species Estero Real orthonairovirus was created for Estero Real virus (ERV) (moved from genus Orthobunyavirus, family Peribunyaviridae) [1] (TaxoProp 2018.012M.A.v1.Bunyavirales_spmov).

\section{Peribunyaviridae}

The family was expanded by one new genus, Pacuvirus, to accommodate three new species: Pacui pacuvirus for Pacui virus (PACV) discovered in a rice rat (Oryzomys sp.); Rio Preto da Eva pacuvirus for Rio Preto da Eva virus discovered in a sewer gnat (Psychodidae sp.); and Tapirape pacuvirus for Tapirapé virus found in a hocicudo (Oxymycterus sp.) [27] (TaxoProp 2018.017M.A.v1. Bunyavirales_2fam5gen). Genus Tospovirus was removed from the family and placed into the new family Tospoviridae as genus Orthotospovirus (TaxoProp 2018.017M.A.v1. Bunyavirales_2fam5gen). The genus Orthobunyavirus was reorganized by moving previously classified viruses into a total of 38 new species (one resulting from a merger of two previously established species) (TaxoProp 2018.008M.A.v1. Orthobunyavirus_38sp). Five additional novel species were added: Bellavista orthobunyavirus for Bellavista virus isolated from mosquitoes (Culex portesi) [14]; Enseada orthobunyavirus for Enseada virus isolated from Culex mosquitoes [4, 9]; Maguari orthobunyavirus for Maguari virus (MAGV) isolated from mosquitoes [13]; Tataguine orthobunyavirus for Tataguine virus (TATV) found in a human sample, and Witwatersrand orthobunyavirus for Witwatersrand virus (WITV) from mosquitoes [29] (TaxoProp 2018.017M.A.v1.Bunyavirales_2fam5gen). Species Estero
Real orthobunyavirus was abolished, and its member, Estero Real virus (ERV), was moved into family Nairoviridae [1] (TaxoProp 2018.012M.A.v1.Bunyavirales_spmov).

\section{Phasmaviridae}

The family was expanded by addition of one new genus, Sawastrivirus, to include one new species, Sanxia sawastrivirus, for Sānxiá water strider virus 2 (SxWSV-2) (TaxoProp 2018.017M.A.v1.Bunyavirales_2fam5gen) detected in gerrid water striders [31]. The genus Orthophasmavirus was expanded by the addition of five new species: Culex orthophasmavirus for Culex phasma-like virus (CPLV) detected in Culex mosquitoes [32]; Ganda orthophasmavirus for Ganda bee virus (GBEEV) of European orchard bees (Osmia cornuta) [28]; Odonate orthophasmavirus for Húběi odonate virus 8 (HbOV-8) [31]; Qingling orthophasmavirus for Húběi odonate virus 9 (HbOV-9) of odonates [31]; and Seattle orthophasmavirus for Seattle Prectang virus (SEPV) found in a moth (Pasiphila rectangulata) [21] (TaxoProp 2018.009M.A.v1.Phasmavirus_5sp).

\section{Phenuiviridae}

The family Phenuiviridae was expanded by addition of three new genera. Genus Kabutovirus was created to include two new species, Huangpi kabutovirus and Kabuto mountain kabutovirus, for Huángpí tick virus 1 (HpTV-1) of ticks (Haemaphysalis doenitzi) [17] and Kabuto mountain virus (KAMV) of ticks (Haemaphysalis flava) [11], respectively. Genus Laulavirus was created to include one species, Laurel Lake laulavirus, for Laurel Lake virus (LLV) of ticks (Ixodes scapularis) [35]. Genus Wenrivirus was created to include one species, Shrimp wenrivirus, for Wēnzhōu shrimp virus 1 (WzSV-1) [17] found in giant tiger prawns (Penaeus monodon) [17] (TaxoProp 2018.017M.A.v1.Bunyavirales_2fam5gen). The established genus Banyangvirus was expanded by two species, Guertu banyangvirus and Heartland banyangvirus, for Guertu virus (GTV) found in Dermacentor nuttalli ticks [30] and Heartland virus (HRTV), a tick-borne virus originally discovered in human samples [24], respectively (TaxoProp 2018.013M.A.v1.Banyangvirus_sp; TaxoProp 2018.017M.A.v1.Bunyavirales_2fam5gen). Genus Phlebovirus was expanded by one species, Mukawa phlebovirus, for Mukawa virus (MKWV) of ticks (Ixodes persulcatus) [22] (TaxoProp 2018.014M.A.v1.Phlebovirus_sp). In genus Phasivirus, species Wuhan fly phasivirus was abolished (TaxoProp 2018.019M.A.v1.Phenuiviridae_Remsp). 
Table 1 ICTV-accepted taxonomy of the order Bunyavirales as of February 2019. Listed are all bunyaviruses that are classified into species

\begin{tabular}{|c|c|c|}
\hline Family/subfamily/genus & Species ${ }^{\text {II }}$ & Virus (abbreviation) $)^{\mathbb{I}}$ \\
\hline \multicolumn{3}{|l|}{ Family Arenaviridae } \\
\hline \multirow[t]{2}{*}{ Antennavirus } & Hairy antennavirus & Wēnlǐng frogfish arenavirus 2 (WlFAV-2) \\
\hline & Striated antennavirus* & Wēnlǐng frogfish arenavirus 1 (WIFAV-1) \\
\hline Hartmanivirus & Haartman hartmanivirus* & Haartman Institute snake virus 1 (HISV-1) \\
\hline \multirow[t]{42}{*}{ Mammarenavirus } & Allpahuayo mammarenavirus & Allpahuayo virus (ALLV) \\
\hline & Argentinian mammarenavirus & Junín virus (JUNV) \\
\hline & Bear Canyon mammarenavirus & Bear Canyon virus (BCNV) \\
\hline & Brazilian mammarenavirus & Sabiá virus (SBAV) \\
\hline & Cali mammarenavirus & Pichindé virus (PICHV) \\
\hline & Chapare mammarenavirus & Chapare virus (CHAPV) \\
\hline & Cupixi mammarenavirus & Cupixi virus (CUPXV) \\
\hline & Flexal mammarenavirus & Flexal virus (FLEV) \\
\hline & Gairo mammarenavirus & Gairo virus (GAIV) \\
\hline & Guanarito mammarenavirus & Guanarito virus (GTOV) \\
\hline & Ippy mammarenavirus & Ippy virus (IPPYV) \\
\hline & Lassa mammarenavirus & Lassa virus (LASV) \\
\hline & Latino mammarenavirus & Latino virus (LATV) \\
\hline & Loei River mammarenavirus & Loei River virus (LORV) \\
\hline & Lujo mammarenavirus & Lujo virus (LUJV) \\
\hline & Luna mammarenavirus & Luli virus (LULV) \\
\hline & & Luna virus (LUAV) \\
\hline & Lunk mammarenavirus & Lunk virus (LNKV) \\
\hline & Lymphocytic choriomeningitis mammarenavirus* & Dandenong virus (DANV) \\
\hline & & lymphocytic choriomeningitis virus (LCMV) \\
\hline & Machupo mammarenavirus & Machupo virus (MACV) \\
\hline & Mariental mammarenavirus & Mariental virus (MRLV) \\
\hline & Merino Walk mammarenavirus & Merino Walk virus (MRWV) \\
\hline & Mobala mammarenavirus & mobala virus (MOBV) \\
\hline & Mopeia mammarenavirus & Mopeia virus (MPOV) \\
\hline & & Morogoro virus (MORV) \\
\hline & Okahandja mammarenavirus & Okahandja virus (OKAV) \\
\hline & Oliveros mammarenavirus & Oliveros virus (OLVV) \\
\hline & Paraguayan mammarenavirus & Paraná virus (PRAV) \\
\hline & Pirital mammarenavirus & Pirital virus (PIRV) \\
\hline & Ryukyu mammarenavirus & Ryukyu virus (RYKV) \\
\hline & Serra do Navio mammarenavirus & Amaparí virus (AMAV) \\
\hline & Solwezi mammarenavirus & Solwezi virus (SOLV) \\
\hline & Souris mammarenavirus & souris virus (SOUV) \\
\hline & Tacaribe mammarenavirus & Tacaribe virus (TCRV) \\
\hline & Tamiami mammarenavirus & Tamiami virus (TMMV) \\
\hline & Wenzhou mammarenavirus & Wēnzhōu virus (WENV) \\
\hline & Whitewater Arroyo mammarenavirus & Big Brushy Tank virus (BBRTV) \\
\hline & & Catarina virus (CTNV) \\
\hline & & Skinner Tank virus (SKTV) \\
\hline & & Tonto Creek virus (TTCV) \\
\hline & & Whitewater Arroyo virus (WWAV) \\
\hline \multirow[t]{8}{*}{ Reptarenavirus } & California reptarenavirus & CAS virus (CASV) \\
\hline & Giessen reptarenavirus & University of Giessen virus 1 (UGV-1) \\
\hline & & University of Giessen virus 2 (UGV-2) \\
\hline & & University of Giessen virus 3 (UGV-3) \\
\hline & Golden reptarenavirus* & Golden Gate virus (GOGV) \\
\hline & Ordinary reptarenavirus & tavallinen suomalainen mies virus 2 (TSMV-2) \\
\hline & Rotterdam reptarenavirus & ROUT virus (ROUTV) \\
\hline & & University of Helsinki virus 1 (UHV-1) \\
\hline
\end{tabular}


Table 1 (continued)

\begin{tabular}{|c|c|c|}
\hline Family/subfamily/genus & Species ${ }^{\text {II }}$ & Virus (abbreviation) $)^{\mathrm{g}}$ \\
\hline \multicolumn{3}{|l|}{ Family Cruliviridae } \\
\hline Lincruvirus & Crustacean lincruvirus* & Wēnlı̌ng crustacean virus 9 (W1CV-9) \\
\hline \multicolumn{3}{|l|}{ Family Fimoviridae } \\
\hline \multirow[t]{9}{*}{ Emaravirus } & Actinidia chlorotic ringspot-associated emaravirus & Actinidia chlorotic ringspot-associated virus (AcCRaV) \\
\hline & European mountain ash ringspot-associated emaravirus* & European mountain ash ringspot-associated virus (EMARaV) \\
\hline & Fig mosaic emaravirus & fig mosaic virus (FMV) \\
\hline & High Plains wheat mosaic emaravirus & High Plains wheat mosaic virus (HPWMoV) \\
\hline & Pigeonpea sterility mosaic emaravirus 1 & pigeonpea sterility mosaic virus (PPSMV) \\
\hline & Pigeonpea sterility mosaic emaravirus 2 & pigeonpea sterility mosaic virus 2 (PPSMV-2) \\
\hline & Raspberry leaf blotch emaravirus & raspberry leaf blotch virus (RLBV) \\
\hline & Redbud yellow ringspot-associated emaravirus & redbud yellow ringspot-associated virus (RYRaV) \\
\hline & Rose rosette emaravirus & rose rosette virus (RRV) \\
\hline \multicolumn{3}{|l|}{ Family Hantaviridae } \\
\hline \multicolumn{3}{|l|}{ Subfamily Actantavirinae } \\
\hline \multirow[t]{3}{*}{ Actinovirus } & Batfish actinovirus* & Wēnlǐng minipizza batfish virus (WEMBV) \\
\hline & Goosefish actinovirus & Wēnlǐng yellow goosefish virus (WEYGV) \\
\hline & Spikefish actinovirus & Wēnlǐng red spikefish virus (WERSV) \\
\hline \multicolumn{3}{|l|}{ Subfamily Agantavirinae } \\
\hline Agnathovirus & Hagfish agnathovirus* & Wēnlǐng hagfish virus (WEHV) \\
\hline \multicolumn{3}{|c|}{ Subfamily Mammantavirinae } \\
\hline Loanvirus & Longquan loanvirus* & Lóngquán virus (LQUV) \\
\hline \multirow[t]{3}{*}{ Mobatvirus } & Laibin mobatvirus & Láibīn virus (LAIV) \\
\hline & Nova mobatvirus* & Nova virus (NVAV) \\
\hline & Quezon mobatvirus & Quezon virus (QZNV) \\
\hline \multirow[t]{29}{*}{ Orthohantavirus } & Andes orthohantavirus & Andes virus (ANDV) \\
\hline & & Castelo dos Sonhos virus (CASV) \\
\hline & & Lechiguanas virus $(\mathrm{LECV}=\mathrm{LECHV})$ \\
\hline & & Orán virus (ORNV) \\
\hline & Asama orthohantavirus & Asama virus (ASAV) \\
\hline & Asikkala orthohantavirus & Asikkala virus (ASIV) \\
\hline & Bayou orthohantavirus & bayou virus (BAYV) \\
\hline & & Catacamas virus (CATV) \\
\hline & Black Creek Canal orthohantavirus & Black Creek Canal virus (BCCV) \\
\hline & Bowe orthohantavirus & Bowé virus (BOWV) \\
\hline & Bruges orthohantavirus & Bruges virus (BRGV) \\
\hline & Cano Delgadito orthohantavirus & Caño Delgadito virus (CADV) \\
\hline & Cao Bang orthohantavirus & Cao Bằng virus (CBNV) \\
\hline & & Liánghé virus (LHEV) \\
\hline & Choclo orthohantavirus & Choclo virus (CHOV) \\
\hline & Dabieshan orthohantavirus & Dàbiéshān virus (DBSV) \\
\hline & Dobrava-Belgrade orthohantavirus & Dobrava virus (DOBV) \\
\hline & & Kurkino virus (KURV) \\
\hline & & Saaremaa virus (SAAV) \\
\hline & & Sochi virus (SOCV) \\
\hline & El Moro Canyon orthohantavirus & Carrizal virus (CARV) \\
\hline & & El Moro Canyon virus (ELMCV) \\
\hline & & Huitzilac virus (HUIV) \\
\hline & Fugong orthohantavirus & Fúgòng virus (FUGV) \\
\hline & Fusong orthohantavirus & Fǔsōng virus (FUSV) \\
\hline & Hantaan orthohantavirus* & Amur virus (AMRV) \\
\hline & & Hantaan virus (HTNV) \\
\hline & & Soochong virus (SOOV) \\
\hline & Jeju orthohantavirus & Jeju virus (JJUV) \\
\hline
\end{tabular}


Table 1 (continued)

\begin{tabular}{|c|c|c|}
\hline Family/subfamily/genus & Species $^{\text {Tl }}$ & Virus (abbreviation) $)^{\mathrm{II}}$ \\
\hline & Kenkeme orthohantavirus & Kenkeme virus (KKMV) \\
\hline & \multirow[t]{2}{*}{ Khabarovsk orthohantavirus } & Khabarovsk virus (KHAV) \\
\hline & & Topografov virus (TOPV) \\
\hline & \multirow[t]{3}{*}{ Laguna Negra orthohantavirus } & Laguna Negra virus (LANV) \\
\hline & & Maripa virus (MARV) \\
\hline & & Río Mamoré virus (RIOMV) \\
\hline & Luxi orthohantavirus & Lúxī virus (LUXV) \\
\hline & Maporal orthohantavirus & Maporal virus (MAPV) \\
\hline & Montano orthohantavirus & Montaño virus (MTNV) \\
\hline & Necocli orthohantavirus & Necoclí virus (NECV) \\
\hline & Oxbow orthohantavirus & Oxbow virus (OXBV) \\
\hline & Prospect Hill orthohantavirus & Prospect Hill virus (PHV) \\
\hline & \multirow[t]{3}{*}{ Puumala orthohantavirus } & Hokkaido virus (HOKV) \\
\hline & & Muju virus (MUJV) \\
\hline & & Puumala virus (PUUV) \\
\hline & Rockport orthohantavirus & Rockport virus (RKPV) \\
\hline & Sangassou orthohantavirus & Sangassou virus (SANGV) \\
\hline & Seewis orthohantavirus & Seewis virus (SWSV) \\
\hline & \multirow[t]{2}{*}{ Seoul orthohantavirus } & gōu virus (GOUV) \\
\hline & & Seoul virus (SEOV) \\
\hline & \multirow[t]{2}{*}{ Sin Nombre orthohantavirus } & New York virus (NYV) \\
\hline & & Sin Nombre virus (SNV) \\
\hline & \multirow[t]{3}{*}{ Thailand orthohantavirus } & Anjozorobe virus (ANJZV) \\
\hline & & Serang virus (SERV) \\
\hline & & Thailand virus (THAIV) \\
\hline & Tigray orthohantavirus & Tigray virus (TIGV) \\
\hline & \multirow[t]{2}{*}{ Tula orthohantavirus } & Adler virus (ADLV) \\
\hline & & Tula virus (TULV) \\
\hline & Yakeshi orthohantavirus & Yákèshí virus (YKSV) \\
\hline \multirow[t]{2}{*}{ Thottimvirus } & Imjin thottimvirus & Imjin virus (MJNV) \\
\hline & Thottapalayam thottimvirus* & Thottapalayam virus (TPMV) \\
\hline \multicolumn{3}{|l|}{ Subfamily Repantavirinae } \\
\hline Reptillovirus & Gecko reptillovirus* & Hăinán oriental leaf-toed gecko virus (HOLGV) \\
\hline \multicolumn{3}{|l|}{ Family Leishbuviridae } \\
\hline Shilevirus & Leptomonas shilevirus* & $\begin{array}{l}\text { Leptomonas moramango virus } \\
\text { (LEPMV) }\end{array}$ \\
\hline \multicolumn{3}{|l|}{ Family Mypoviridae } \\
\hline Hubavirus & Myriapod hubavirus* & Húběi myriapoda virus 5 (HbMV-5) \\
\hline \multicolumn{3}{|l|}{ Family Nairoviridae } \\
\hline \multirow[t]{15}{*}{ Orthonairovirus } & Artashat orthonairovirus & Artashat virus (ARTSV) \\
\hline & Chim orthonairovirus & Chim virus (CHIMV) \\
\hline & Crimean-Congo hemorrhagic fever orthonairovirus & Crimean-Congo hemorrhagic fever virus (CCHFV) \\
\hline & \multirow[t]{4}{*}{ Dera Ghazi Khan orthonairovirus } & Abu Hammad virus (AHV) \\
\hline & & Abu Mina virus (AMV) \\
\hline & & Dera Ghazi Khan virus (DGKV) \\
\hline & & Sapphire II virus (SAPV) \\
\hline & \multirow[t]{2}{*}{ Dugbe orthonairovirus* } & Dugbe virus (DUGV) \\
\hline & & kupe virus (KUPEV) \\
\hline & Estero Real orthonairovirus & Estero Real virus (ERV) \\
\hline & \multirow[t]{2}{*}{ Hazara orthonairovirus } & Hazara virus (HAZV) \\
\hline & & Tofla virus (TFLV) \\
\hline & \multirow[t]{3}{*}{ Hughes orthonairovirus } & Caspiy virus (CASV) \\
\hline & & Farallon virus (FARV) \\
\hline & & Great Saltee virus (GRSV) \\
\hline
\end{tabular}


Table 1 (continued)

\begin{tabular}{|c|c|c|}
\hline Family/subfamily/genus & Species" & Virus (abbreviation) ${ }^{\mathrm{T}}$ \\
\hline & & Hughes virus (HUGV) \\
\hline & & Punta Salinas virus (PSV) \\
\hline & & Raza virus (RAZAV) \\
\hline & & Soldado virus (SOLV) \\
\hline & & Zirqa virus (ZIRV) \\
\hline & Kasokero orthonairovirus & Kasokero virus (KASV $=$ KASOV) \\
\hline & & Leopards Hill virus (LPHV) \\
\hline & & Yogue virus (YOGV) \\
\hline & Keterah orthonairovirus & Gossas virus (GOSV) \\
\hline & & Issyk-kul virus (ISKV) \\
\hline & & Keterah virus (KTRV) \\
\hline & & Uzun-Agach virus (UZAV) \\
\hline & Nairobi sheep disease orthonairovirus & Nairobi sheep disease virus (NSDV) \\
\hline & Qalyub orthonairovirus & Bandia virus (BDAV) \\
\hline & & Geran virus (GERV) \\
\hline & & Qalyub virus (QYBV) \\
\hline & Sakhalin orthonairovirus & Avalon virus (AVAV) \\
\hline & & Clo Mor virus $(\mathrm{CMV}=\mathrm{CLMV})$ \\
\hline & & Sakhalin virus (SAKV) \\
\hline & & Taggert virus (TAGV) \\
\hline & & Tillamook virus (TILLV) \\
\hline & Tamdy orthonairovirus & Burana virus (BURV) \\
\hline & & Huángpí tick virus 1 (HpTV-1) \\
\hline & & Tăchéng tick virus 1 (TcTV-1) \\
\hline & & Tamdy virus (TAMV) \\
\hline & & Wēnzhōu tick virus (WzTV) \\
\hline & Thiafora orthonairovirus & Erve virus (ERVEV) \\
\hline & & Thiafora virus (TFAV) \\
\hline Shaspivirus & Spider shaspivirus* & Shāyáng spider virus 1 (SySV-1) \\
\hline Striwavirus & Strider striwavirus* & Sānxiá water strider virus 1 (SxWSV-1) \\
\hline \multicolumn{3}{|l|}{ Family Peribunyaviridae } \\
\hline \multirow[t]{3}{*}{ Herbevirus } & Herbert herbevirus* & Herbert virus (HEBV) \\
\hline & Kibale herbevirus & Kibale virus (KIBV) \\
\hline & Tai herbevirus & Taï virus (TAIV) \\
\hline \multirow[t]{21}{*}{ Orthobunyavirus } & Acara orthobunyavirus & Acará virus (ACAV) \\
\hline & & Moriche virus (MORV) \\
\hline & Aino orthobunyavirus & Aino virus (AINOV) \\
\hline & Akabane orthobunyavirus & Akabane virus (AKAV) \\
\hline & & Tinaroo virus (TINV) \\
\hline & & Yaba-7 virus $(\mathrm{Y} 7 \mathrm{~V})$ \\
\hline & Alajuela orthobunyavirus & Alajuela virus (ALJV) \\
\hline & & San Juan virus (SJV) \\
\hline & Anadyr orthobunyavirus & Anadyr virus (ANADV) \\
\hline & Anhembi orthobunyavirus & Anhembi virus (AMBV) \\
\hline & Anopheles A orthobunyavirus & Anopheles A virus (ANAV) \\
\hline & & Arumateua virus $(\mathrm{ARTV}=\mathrm{ARMTV})$ \\
\hline & & Caraipé virus $(\mathrm{CPEV}=\mathrm{CRPV})$ \\
\hline & & Las Maloyas virus (LMV) \\
\hline & & Lukuni virus (LUKV) \\
\hline & & Trombetas virus (TRMV) \\
\hline & & Tucuruí virus (TUCV = TUCRV) \\
\hline & Anopheles B orthobunyavirus & Anopheles B virus (ANBV) \\
\hline & & Boracéia virus (BORV) \\
\hline & Bakau orthobunyavirus & Bakau virus (BAKV) \\
\hline & & Ketapang virus (KETV) \\
\hline
\end{tabular}


Table 1 (continued)

\begin{tabular}{|c|c|c|}
\hline Family/subfamily/genus & Species" & Virus (abbreviation) $)^{\mathrm{Il}}$ \\
\hline & & Nola virus (NOLAV) \\
\hline & & Tanjong Rabok virus (TRV) \\
\hline & & Telok Forest virus (TFV) \\
\hline & Batai orthobunyavirus & Batai virus (BATV) \\
\hline & Batama orthobunyavirus & Batama virus (BMAV) \\
\hline & Bellavista orthobunyavirus & Bellavista virus (BELLV) \\
\hline & Benevides orthobunyavirus & Benevides virus $(\mathrm{BVSV}=\mathrm{BENV})$ \\
\hline & Bertioga orthobunyavirus & Bertioga virus (BERV) \\
\hline & & Cananéia virus (CNAV) \\
\hline & & Guaratuba virus (GTBV) \\
\hline & & Itimirim virus (ITIV) \\
\hline & & Mirim virus (MIRV) \\
\hline & Bimiti orthobunyavirus & bimiti virus (BIMV) \\
\hline & Birao orthobunyavirus & Birao virus (BIRV) \\
\hline & Botambi orthobunyavirus & Botambi virus (BOTV) \\
\hline & Bozo orthobunyavirus & Bozo virus (BOZOV) \\
\hline & Bunyamwera orthobunyavirus* & Bunyamwera virus (BUNV) \\
\hline & & Germiston virus (GERV) \\
\hline & & Lokern virus (LOKV) \\
\hline & & Mboké virus (MBOV) \\
\hline & & Ngari virus (NRIV) \\
\hline & & Northway virus (NORV) \\
\hline & & Santa Rosa virus (SARV) \\
\hline & & Shokwe virus (SHOV) \\
\hline & & Stanfield virus (STAV) \\
\hline & & Xingu virus (XINV) \\
\hline & Bushbush orthobunyavirus & Benfica virus $(\mathrm{BENV}=\mathrm{BNFV})$ \\
\hline & & Bushbush virus (BSBV) \\
\hline & & Juan Díaz virus (JDV) \\
\hline & Buttonwillow orthobunyavirus & Buttonwillow virus (BUTV) \\
\hline & Bwamba orthobunyavirus & Bwamba virus (BWAV) \\
\hline & & Pongola virus (PGAV) \\
\hline & Cache Valley orthobunyavirus & Cache Valley virus (CVV) \\
\hline & & Cholul virus (CHLV) \\
\hline & & Tlacotalpan virus (TLAV) \\
\hline & Cachoeira Porteira orthobunyavirus & Cachoeira Porteira virus (CPOV) \\
\hline & California encephalitis orthobunyavirus & California encephalitis virus (CEV) \\
\hline & & Morro Bay virus (MBV) \\
\hline & Capim orthobunyavirus & Capim virus (CAPV) \\
\hline & Caraparu orthobunyavirus & Apeú virus (APEUV) \\
\hline & & Bruconha virus (BRUV) \\
\hline & & Caraparú virus (CARV) \\
\hline & & El Huayo virus (EHUV) \\
\hline & & Itaya virus (ITYV) \\
\hline & & Ossa virus (OSSAV) \\
\hline & & Vinces virus (VINV) \\
\hline & Cat Que orthobunyavirus & Cát Quế virus (CQV) \\
\hline & & Oya virus (OYAV) \\
\hline & Catu orthobunyavirus & Catú virus (CATUV) \\
\hline & Enseada orthobunyavirus & Enseada virus (ENSV) \\
\hline & Faceys paddock orthobunyavirus & Facey’s paddock virus (FPV) \\
\hline & Fort Sherman orthobunyavirus & Fort Sherman virus (FSV) \\
\hline & Gamboa orthobunyavirus & Brus Laguna virus (BLAV) \\
\hline & & Calchaquí virus (CQIV) \\
\hline & & Gamboa virus (GAMV) \\
\hline
\end{tabular}


Table 1 (continued)

\begin{tabular}{|c|c|c|}
\hline Family/subfamily/genus & Species" & Virus (abbreviation) $)^{\mathrm{Il}}$ \\
\hline & & Pueblo Viejo virus (PVV) \\
\hline & & Soberanía virus (SOBV) \\
\hline & Guajara orthobunyavirus & Guajará virus (GJAV) \\
\hline & Guama orthobunyavirus & Ananindeua virus (ANUV) \\
\hline & & Guamá virus (GMAV) \\
\hline & & Mahogany Hammock virus (MHV) \\
\hline & & Moju virus (MOJUV) \\
\hline & Guaroa orthobunyavirus & Guaroa virus (GROV) \\
\hline & Iaco orthobunyavirus & Iaco virus (IACOV) \\
\hline & Ilesha orthobunyavirus & Ilesha virus (ILEV) \\
\hline & Ingwavuma orthobunyavirus & Ingwavuma virus (INGV) \\
\hline & Jamestown Canyon orthobunyavirus & Inkoo virus (INKV) \\
\hline & & Jamestown Canyon virus (JCV) \\
\hline & & Jerry Slough virus (JSV) \\
\hline & & South River virus (SORV) \\
\hline & Jatobal orthobunyavirus & Jatobal virus (JATV) \\
\hline & Kaeng Khoi orthobunyavirus & Kaeng Khoi virus (KKV) \\
\hline & Kairi orthobunyavirus & Kairi virus (KRIV) \\
\hline & Keystone orthobunyavirus & Keystone virus (KEYV) \\
\hline & Koongol orthobunyavirus & koongol virus (KOOV) \\
\hline & & wongal virus (WONV) \\
\hline & La Crosse orthobunyavirus & La Crosse virus (LACV) \\
\hline & Leanyer orthobunyavirus & Leanyer virus (LEAV) \\
\hline & Lumbo orthbunyavirus & Lumbo virus (LUMV) \\
\hline & Macaua orthobunyavirus & Macauã virus (MCAV) \\
\hline & Madrid orthobunyavirus & Madrid virus (MADV) \\
\hline & Maguari orthobunyavirus & Maguari virus (MAGV) \\
\hline & & Playas virus (PLAV) \\
\hline & Main Drain orthobunyavirus & Main Drain virus (MDV) \\
\hline & Manzanilla orthobunyavirus & Manzanilla virus (MANV) \\
\hline & & Inini virus (INIV) \\
\hline & Marituba orthobunyavirus & Gumbo Limbo virus (GLV) \\
\hline & & Marituba virus (MTBV) \\
\hline & & Murutucú virus (MURV) \\
\hline & & Nepuyo virus (NEPV) \\
\hline & & Restan virus (RESV) \\
\hline & & Zungarococha virus (ZUNV) \\
\hline & Melao orthobunyavirus & Melao virus (MELV) \\
\hline & Mermet orthobunyavirus & Mermet virus (MERV) \\
\hline & Minatitlan orthobunyavirus & Minatitlán virus (MNTV) \\
\hline & & Palestina virus (PLSV) \\
\hline & MPoko orthobunyavirus & M'Poko virus (MPOV) \\
\hline & & Yaba-1 virus (Y1V) \\
\hline & Nyando orthobunyavirus & Eretmapodites virus (ERETV) \\
\hline & & Mojuí dos Campos virus (MDCV) \\
\hline & & Nyando virus (NDV) \\
\hline & Olifantsvlei orthobunyavirus & Bobia virus (BIAV) \\
\hline & & Dabakala virus (DABV) \\
\hline & & Olifantsvlei virus (OLIV) \\
\hline & & Oubi virus (OUBIV) \\
\hline & Oriboca orthobunyavirus & Itaquí virus (ITQV) \\
\hline & & Oriboca virus (ORIV) \\
\hline & Oropouche orthobunyavirus & Iquitos virus (IQTV) $^{\mathrm{d}}$ \\
\hline & & Madre de Dios virus (MDDV) \\
\hline & & Oropouche virus (OROV) \\
\hline
\end{tabular}


Table 1 (continued)

\begin{tabular}{|c|c|c|}
\hline Family/subfamily/genus & Species ${ }^{\pi}$ & Virus (abbreviation) $)^{\mathrm{I}}$ \\
\hline & \multirow{7}{*}{ Patois orthobunyavirus } & Perdões virus (PDEV) \\
\hline & & Pintupo virus (PINTV) \\
\hline & & Abras virus (ABRV) \\
\hline & & Babahoya virus (BABV) \\
\hline & & Pahayokee virus (PAHV) \\
\hline & & Patois virus (PATV) \\
\hline & & Shark River virus (SRV) \\
\hline & Peaton orthobunyavirus & Peaton virus (PEAV) \\
\hline & Potosi orthobunyavirus & Potosi virus (POTV) \\
\hline & Sabo orthobunyavirus & Sabo virus (SABOV) \\
\hline & San Angelo orthobunyavirus & San Angelo virus (SAV) \\
\hline & Sango orthobunyavirus & Sango virus (SANV) \\
\hline & \multirow[t]{4}{*}{ Schmallenberg orthobunyavirus } & Douglas virus (DOUV) \\
\hline & & Sathuperi virus (SATV) \\
\hline & & Schmallenberg virus (SBV) \\
\hline & & Shamonda virus (SHAV) \\
\hline & Serra do Navio orthobunyavirus & Serra do Navio virus (SDNV) \\
\hline & \multirow[t]{2}{*}{ Shuni orthobunyavirus } & Kaikalur virus (KAIV) \\
\hline & & Shuni virus (SHUV) \\
\hline & \multirow[t]{2}{*}{ Simbu orthobunyavirus } & Para virus (PARAV) \\
\hline & & Simbu virus (SIMV) \\
\hline & \multirow[t]{2}{*}{ Snowshoe hare orthobunyavirus } & Khatanga virus (KHATV) ${ }^{9}$ \\
\hline & & snowshoe hare virus (SSHV) \\
\hline & Sororoca orthobunyavirus & Sororoca virus (SORV) \\
\hline & \multirow[t]{4}{*}{ Tacaiuma orthobunyavirus } & CoAr 1071 virus (CA1071V) \\
\hline & & CoAr 3627 virus (CA3626V) \\
\hline & & Tacaiuma virus (TCMV) \\
\hline & & Virgin River virus (VRV) \\
\hline & Tahyna orthobunyavirus & Ťahyňa virus (TAHV) \\
\hline & Tataguine orthobunyavirus & Tataguine virus (TATV) \\
\hline & Tensaw orthobunyavirus & Tensaw virus (TENV) \\
\hline & \multirow[t]{5}{*}{ Tete orthobunyavirus } & Bahig virus (BAHV) \\
\hline & & Matruh virus (MTRV) \\
\hline & & Tete virus (TETEV) \\
\hline & & Tsuruse virus (TSUV) \\
\hline & & Weldona virus (WELV) \\
\hline & Thimiri orthobunyavirus & Thimiri virus (THIV) \\
\hline & Timboteua orthobunyavirus & Timboteua virus (TBTV) \\
\hline & \multirow[t]{2}{*}{ Trivittatus orthobunyavirus } & Achiote virus (ACHOV) \\
\hline & & Trivittatus virus (TVTV) \\
\hline & \multirow[t]{3}{*}{ Turlock orthobunyavirus } & Lednice virus (LEDV) \\
\hline & & Turlock virus (TURV) \\
\hline & & Umbre virus (UMBV) \\
\hline & Utinga orthobunyavirus & Utinga virus (UTIV) \\
\hline & Witwatersrand orthobunyavirus & Witwatersrand virus (WITV) \\
\hline & Wolkberg orthobunyavirus & Wolkberg virus (WBV) \\
\hline & \multirow[t]{4}{*}{ Wyeomyia orthobunyavirus } & Rio Pracupi virus \\
\hline & & Taiassui virus (TAIAV) \\
\hline & & Tucunduba virus (TUCV) \\
\hline & & Wyeomyia virus (WYOV) \\
\hline & Zegla orthobunyavirus & Zegla virus (ZEGV) \\
\hline \multirow[t]{3}{*}{ Pacuvirus } & Pacui pacuvirus* & Pacui virus (PACV) \\
\hline & Rio Preto da Eva pacuvirus & Rio Preto da Eva virus (RPEV) \\
\hline & Tapirape pacuvirus & Tapirapé virus (TAPV) \\
\hline Shangavirus & Insect shangavirus* & Shuāngào insect virus 1 (SgIV-1) \\
\hline
\end{tabular}

\section{Springer}


Table 1 (continued)

\begin{tabular}{|c|c|c|}
\hline Family/subfamily/genus & Species ${ }^{\pi}$ & Virus (abbreviation) $)^{\pi}$ \\
\hline \multicolumn{3}{|l|}{ Family Phasmaviridae } \\
\hline Feravirus & Ferakferavirus $*$ & Ferak virus (FRKV) \\
\hline Inshuvirus & Insect inshuvirus* & Shuāngào insect virus 2 (SgIV-2) \\
\hline Jonvirus & Jonchet jonvirus* & jonchet virus (JONV) \\
\hline \multirow[t]{10}{*}{ Orthophasmavirus } & Culex orthophasmavirus & Culex phasma-like virus (CPLV) \\
\hline & Ganda orthophasmavirus & Ganda bee virus (GBEEV) \\
\hline & Kigluaik phantom orthophasmavirus* & Kigluaik phantom virus (KIGV) \\
\hline & Nome phantom orthophasmavirus & Nome phantom virus (NOMV) \\
\hline & Odonate orthophasmavirus & Húběi odonate virus 8 (HbOV-8) \\
\hline & Qingling orthophasmavirus & Húběi odonate virus 9 (HbOV-9) \\
\hline & Seattle orthophasmavirus & Seattle Prectang virus (SEPV) \\
\hline & Wuchang cockroach orthophasmavirus 1 & Wǔchāng cockroach virus 1 (WcCV-1) \\
\hline & Wuhan mosquito orthophasmavirus 1 & Wǔhàn mosquito virus 1 (WhMV-1) \\
\hline & Wuhan mosquito orthophasmavirus 2 & Wǔhàn mosquito virus 2 (WhMV-2) \\
\hline Sawastrivirus & Sanxia sawastrivirus* & Sānxiá water strider virus 2 (SxWSV-2) \\
\hline Wuhivirus & Insect wuhivirus* & Wǔhàn insect virus 2 (WhIV-2) \\
\hline \multicolumn{3}{|l|}{ Family Phenuiviridae } \\
\hline \multirow[t]{3}{*}{ Banyangvirus } & Guertu banyangvirus & Guertu virus (GTV) \\
\hline & Heartland banyangvirus & Heartland virus (HRTV) \\
\hline & Huaiyangshan banyangvirus* & severe fever with thrombocytopenia syndrome virus (SFTSV) \\
\hline Beidivirus & Dipteran beidivirus* & Húběi diptera virus 3 (HbDV-3) \\
\hline \multirow[t]{3}{*}{ Goukovirus } & Cumuto goukovirus & Cumuto virus (CUMV) \\
\hline & Gouleako goukovirus* & Gouléako virus (GOLV) \\
\hline & Yichang insect goukovirus & Yíchāng insect virus (YcIV) \\
\hline Horwuvirus & Horsefly horwuvirus* & Wǔhàn horsefly virus (WhHV) \\
\hline Hudivirus & Dipteran hudivirus* & Húběi diptera virus 4 (HbDV-4) \\
\hline Hudovirus & Lepidopteran hudovirus* & Húběi lepidoptera virus 1 (HbLV-1) \\
\hline \multirow[t]{2}{*}{ Kabutovirus } & Huangpi kabutovirus* & Huángpí tick virus 2 (HpTV-2) \\
\hline & Kabuto mountain kabutovirus & Kabuto mountain virus (KAMV) \\
\hline Laulavirus & Laurel Lake laulavirus* & Laurel Lake virus (LLV) \\
\hline Mobuvirus & Mothra mobuvirus* & Mothra virus (MTHV) \\
\hline \multirow[t]{3}{*}{ Phasivirus } & Badu phasivirus* & Badu virus (BADUV) \\
\hline & Phasi Charoen-like phasivirus & Phasi Chaeron-like virus (PCLV) \\
\hline & Wutai mosquito phasivirus & Wǔtái mosquito virus (WtMV) \\
\hline \multirow[t]{21}{*}{ Phlebovirus } & Bujaru phlebovirus & Bujaru virus (BUJV) \\
\hline & & Munguba virus (MUNV) \\
\hline & Candiru phlebovirus & Alenquer virus (ALEV) \\
\hline & & Ariquemes virus (ARQV) \\
\hline & & Candirú virus (CDUV) \\
\hline & & Itaituba virus (ITAV) \\
\hline & & Jacundá virus (JCNV) \\
\hline & & Maldonado virus (MLOV) \\
\hline & & Morumbi virus (MR(M)BV) \\
\hline & & Mucura virus (MCRV/MRAV) \\
\hline & & Nique virus (NIQV) \\
\hline & & Oriximiná virus (ORXV) \\
\hline & & Serra Norte virus (SRNV) \\
\hline & & Turuna virus (TUAV) \\
\hline & Chilibre phlebovirus & Cacao virus (CACV) \\
\hline & & Chilibre virus (CHIV) \\
\hline & Frijoles phlebovirus & Frijoles virus (FRIV) \\
\hline & & Joá virus (JOAV) \\
\hline & Mukawa phlebovirus & Mukawa virus (MKWV) \\
\hline & Punta Toro phlebovirus & Buenaventura virus (BUEV) \\
\hline & & Campana virus (CMAV) \\
\hline
\end{tabular}


Table 1 (continued)

\begin{tabular}{|c|c|c|}
\hline Family/subfamily/genus & Species $^{\mathrm{T}}$ & Virus (abbreviation) ${ }^{\pi}$ \\
\hline & & Capira virus (CAPIV) \\
\hline & & Coclé virus (CCLV) \\
\hline & & Leticia virus (LTCV) \\
\hline & & Punta Toro virus (PTV) \\
\hline & Rift Valley fever phlebovirus* & Rift Valley fever virus (RVFV) \\
\hline & Salehabad phlebovirus & Adana virus (ADAV) \\
\hline & & Adria virus (ADRV) \\
\hline & & Alcube virus \\
\hline & & Arbia virus (ARBV) \\
\hline & & Arumowot virus (AMTV) \\
\hline & & Bregalaka virus (BREV) \\
\hline & & Medjerda Valley virus (MVV) \\
\hline & & Odrénisrou virus (ODRV) \\
\hline & & Olbia virus (OLBV) \\
\hline & & Salehabad virus (SALV) \\
\hline & & Zaba virus (ZABAV) \\
\hline & Sandfly fever Naples phlebovirus & Arrábida virus (ARRV) \\
\hline & & Balkan virus (BALKV) \\
\hline & & Fermo virus (FERV) \\
\hline & & Gordil virus (GORV) \\
\hline & & Granada virus $(\mathrm{GRV}=\mathrm{GRAV})$ \\
\hline & & Massilia virus (MASV) \\
\hline & & Punique virus (PUNV) \\
\hline & & Saddaguia virus (SADV) \\
\hline & & Saint-Floris virus (SAFV) \\
\hline & & sandfly fever Naples virus (SFNV) \\
\hline & & Tehran virus (THEV) \\
\hline & & Toscana virus (TOSV) \\
\hline & & Zerdali virus (ZERV) \\
\hline & Uukuniemi phlebovirus & Chizé virus (CHZV) \\
\hline & & EgAN $1825-61$ virus (EGAV) \\
\hline & & Fin V 707 virus (FINV) \\
\hline & & Oceanside virus $(\mathrm{OCV}=\mathrm{OCEV})$ \\
\hline & & Pontevès virus (PTVV) \\
\hline & & St. Abbs Head virus (SAHV) \\
\hline & & Uukuniemi virus (UUKV) \\
\hline & & Zaliv Terpenyia virus (ZTV) \\
\hline Pidchovirus & Pidgey pidchovirus* & Pidgey virus (PGYV) \\
\hline \multirow[t]{7}{*}{ Tenuivirus } & Echinochloa hoja blanca tenuivirus & Echinochloa hoja blanca virus (EHBV) \\
\hline & Iranian wheat stripe tenuivirus & Iranian wheat stripe virus (IWSV) \\
\hline & Maize stripe tenuivirus & maize stripe virus $(\mathrm{MStV}=\mathrm{MSpV})$ \\
\hline & Rice grassy stunt tenuivirus & rice grassy stunt virus (RGSV) \\
\hline & Rice hoja blanca tenuivirus & rice hoja blanca virus (RHBV) \\
\hline & Rice stripe tenuivirus* & rice stripe virus $(\mathrm{RSV}=\mathrm{RStV})$ \\
\hline & Urochloa hoja blanca tenuivirus & Urochloa hoja blanca virus (UHBV) \\
\hline Wenrivirus & Shrimp wenrivirus* & Wēnzhōu shrimp virus $1 \mathrm{WzSV}-1$ \\
\hline \multirow[t]{2}{*}{ Wubeivirus } & Dipteran wubeivirus* & Húběi diptera virus 5 (HbDV-5) \\
\hline & Fly wubeivirus & Wǔhàn fly virus 1 (WhFV-1) \\
\hline \multicolumn{3}{|l|}{ Family Tospoviridae } \\
\hline \multirow[t]{6}{*}{ Orthotospovirus } & Bean necrotic mosaic orthotospovirus & bean necrotic mosaic virus (BeNMV) \\
\hline & Calla lily chlorotic spot orthotospovirus & calla lily chlorotic spot virus (CCSV) \\
\hline & Capsicum chlorosis orthotospovirus & capsicum chlorosis virus (CaCV) \\
\hline & Chrysanthemum stem necrosis orthotospovirus & chrysanthemum stem necrosis virus (CSNV) \\
\hline & Groundnut bud necrosis tospovirus ${ }^{1}$ & groundnut bud necrosis virus (GBNV) \\
\hline & Groundnut ringspot tospovirus ${ }^{1}$ & groundnut ringspot virus (GRSV) \\
\hline
\end{tabular}


Table 1 (continued)

\begin{tabular}{|c|c|c|}
\hline Family/subfamily/genus & Species ${ }^{\mathrm{I}}$ & Virus (abbreviation) ${ }^{\mathbb{I}}$ \\
\hline & Groundnut yellow spot tospovirus ${ }^{1}$ & groundnut yellow spot virus (GYSV) \\
\hline & Impatiens necrotic spot tospovirus ${ }^{1}$ & impatiens necrotic spot virus (INSV) \\
\hline & Iris yellow spot tospovirus ${ }^{1}$ & iris yellow spot virus (IYSV) \\
\hline & Melon severe mosaic orthotospovirus & melon severe mosaic virus (MSMV) \\
\hline & Melon yellow spot orthotospovirus & melon yellow spot virus (MYSV) \\
\hline & Polygonum ringspot tospovirus ${ }^{1}$ & polygonum ringspot virus (PolRSV) \\
\hline & Soybean vein necrosis orthotospovirus & soybean vein necrosis virus (SVNV) \\
\hline & Tomato chlorotic spot tospovirus ${ }^{1}$ & tomato chlorotic spot virus (TCSV) \\
\hline & Tomato spotted wilt tospovirus ${ }^{* 1}$ & tomato spotted wilt virus (TSWV) \\
\hline & Watermelon bud necrosis tospovirus ${ }^{1}$ & watermelon bud necrosis virus (WBNV) \\
\hline & Watermelon silver mottle tospovirus ${ }^{1}$ & watermelon silver mottle virus (WSMoV) \\
\hline & Zucchini lethal chlorosis tospovirus ${ }^{1}$ & zucchini lethal chlorosis virus (ZLCV) \\
\hline \multicolumn{3}{|l|}{ Family Wupedeviridae } \\
\hline Wumivirus & Millipede wumivirus* & Wǔhàn millipede virus 2 (WhMV-2) \\
\hline \multicolumn{3}{|l|}{ Unassigned } \\
\hline Coguvirus & Citrus coguvirus* & citrus concave gum-associated virus $(\mathrm{CCGaV})$ \\
\hline
\end{tabular}

*type species

${ }^{1}$ Due to a formal classification mistake, this species was not correctly renamed to include the genus epithet "orthotospovirus." A proposal to ensure that all species included in the genus Orthotospovirus are named uniformly ending in "orthotospovirus" will be submitted prior to the next taxonomic proposal submission deadline

IPlease note that viruses are real objects that are assigned to concepts that are called taxa. Species, genera, families, and orders are taxa. Taxon names are always italicized and always begin with a capital letter. Virus names, on the other hand, are not italicized and are not capitalized, except if the name or a name component is a proper noun. This column lists the virus names with their correct (lack of) capitalization. Lists of viruses within a given species are provisional at this point and will likely be amended in the near future

\section{Wupedeviridae}

No changes were made at the family rank.

\section{Summary}

A summary of the current, ICTV-accepted taxonomy of the order Bunyavirales is presented in Table 1.

Acknowledgements We thank Laura Bollinger (NIH/NIAID Integrated Research Facility at Fort Detrick, Frederick, MD, USA) for critically editing the manuscript.

\section{Compliance with ethical standards}

The views and conclusions contained in this document are those of the authors and should not be interpreted as necessarily representing the official policies, either expressed or implied, of the US Department of the Army, the US Department of Defense, the US Department of Health and Human Services, or of the institutions and companies affiliated with the authors. In no event shall any of these entities have any responsibility or liability for any use, misuse, inability to use, or reliance upon the information contained herein. The US departments do not endorse any products or commercial services mentioned in this publication.
Funding This work was supported in part through Battelle Memorial Institute's prime contract with the US National Institute of Allergy and Infectious Diseases (NIAID) under Contract no. HHSN272200700016I (J. H. K.). This work was also funded in part by Grant 109520 by the UK Department of Health, Public Health England (R. H.). W. M. S. is supported by Fundação de Amparo à Pesquisa do Estado de São Paulo, Brazil (17/13981-0). This work was supported by the Intergovernmental Special Program of State Key Research and Development Plan from the Ministry of Science and Technology of China (2016YFE0113500) and European Union's Horizon 2020 EVAg project (no. 653316).

Conflict of interest The authors declare no conflicts of interest.

Ethical approval This article does not contain any studies with human participants or animals performed by any of the authors.

\section{References}

1. Aguilar PV, de Souza WM, Silvas JA, Wood T, Widen S, Fumagalli MJ, Nunes MRT (2018) Genetic characterization of the Patois serogroup (genus Orthobunyavirus; family Peribunyaviridae) and evidence that Estero Real Virus is a member of the genus Orthonairovirus. Am J Trop Med Hyg 99:451-457

2. Akopyants NS, Lye L-F, Dobson DE, Lukeš J, Beverley SM (2016) A novel bunyavirus-like virus of trypanosomatid protist parasites. Genome Announc 4:e00715-e00716

3. Bezerra IC, Resende RdO, Pozzer L, Nagata T, Kormelink R, De Ávila AC (1999) Increase of tospoviral diversity in Brazil with the identification of two new tospovirus species, one from chrysanthemum and one from zucchini. Phytopathology 89:823-830 
4. Calisher CH, Coimbra TLM, Lopez OdS, Muth DJ, Sacchetta LdA, Francy DB, Lazuick JS, Cropp CB (1983) Identification of new Guama and Group $C$ serogroup bunyaviruses and an ungrouped virus from Southern Brazil. Am J Trop Med Hyg 32:424-431

5. Chen CC, Chen TC, Lin YH, Yeh SD, Hsu HT (2005) A chlorotic spot disease on calla lilies (Zantedeschia spp.) is caused by a tospovirus serologically but distantly related to watermelon silver mottle virus. Plant Dis 89:440-445

6. Ciuffo M, Kurowski C, Vivoda E, Copes B, Masenga V, Falk BW, Turina M (2009) A new Tospovirus sp. in cucurbit crops in Mexico. Plant Dis 93:467-474

7. Ciuffo M, Nerva L, Turina M (2017) Full-length genome sequence of the tospovirus melon severe mosaic virus. Arch Virol 162:1419-1422

8. de Oliveira AS, Melo FL, Inoue-Nagata AK, Nagata T, Kitajima EW, Resende RO (2012) Characterization of bean necrotic mosaic virus: a member of a novel evolutionary lineage within the genus Tospovirus. PLoS One 7:e38634

9. de Souza WM, Acrani GO, Romeiro MF, Reis O Jr, Tolardo AL, da Silva SP, de Almeida Medeiros DB, Varela M, Nunes MRT, Figueiredo LTM (2016) Molecular characterization of Capim and Enseada orthobunyaviruses. Infect Genet Evol 40:47-53

10. Dullemans AM, Verhoeven JTJ, Kormelink R, van der Vlugt RAA (2015) The complete nucleotide sequence of chrysanthemum stem necrosis virus. Arch Virol 160:605-608

11. Ejiri H, Lim C-K, Isawa H, Yamaguchi Y, Fujita R, TakayamaIto M, Kuwata R, Kobayashi D, Horiya M, Posadas-Herrera G, Iizuka-Shiota I, Kakiuchi S, Katayama Y, Hayashi T, Sasaki T, Kobayashi M, Morikawa S, Maeda K, Mizutani T, Kaku K, Saijo M, Sawabe K (2018) Isolation and characterization of Kabuto Mountain virus, a new tick-borne phlebovirus from Haemaphysalis flava ticks in Japan. Virus Res 244:252-261

12. Goüy de Bellocq J, Těšíková J, Meheretu Y, Č́ízová D, Bryjová A, Leirs H, Bryja J (2016) Complete genome characterisation and phylogenetic position of Tigray hantavirus from the Ethiopian white-footed mouse, Stenocephalemys albipes. Infect Genet Evol 45:242-245

13. Groseth A, Vine V, Weisend C, Guevara C, Watts D, Russell B, Tesh RB, Ebihara H (2017) Maguari virus associated with human disease. Emerg Infect Dis 23:1325-1331

14. Hang J, Yang Y, Kuschner RA, Evangelista J, Astete H, Halsey ES, Kochel TJ, Forshey BM (2016) Genome sequence of Bellavista virus, a novel orthobunyavirus isolated from a pool of mosquitoes captured near Iquitos, Peru. Genome Announc 4:e01262-e01316

15. Kato K, Handa K, Kameya-Iwaki M (2000) Melon yellow spot virus: a distinct species of the genus Tospovirus isolated from melon. Phytopathology 90:422-426

16. Knierim D, Blawid R, Maiss E (2006) The complete nucleotide sequence of a capsicum chlorosis virus isolate from Lycopersicum esculentum in Thailand. Arch Virol 151:1761-1782

17. Li C-X, Shi M, Tian J-H, Lin X-D, Kang Y-J, Chen L-J, Qin X-C, $\mathrm{Xu}$ J, Holmes EC, Zhang Y-Z (2015) Unprecedented genomic diversity of RNA viruses in arthropods reveals the ancestry of negative-sense RNA viruses. Elife 4:e05378

18. Lin Y-H, Chen T-C, Hsu H-T, Liu F-L, Chu F-H, Chen C-C, Lin Y-Z, Yeh S-D (2005) Serological comparison and molecular characterization for verification of calla lily chlorotic spot virus as a new tospovirus species belonging to Watermelon silver mottle virus serogroup. Phytopathology 95:1482-1488

19. Maes P, Alkhovsky SV, Bào Y, Beer M, Birkhead M, Briese T, Buchmeier MJ, Calisher CH, Charrel RN, Choi IR, Clegg CS, Torre JCDL, Delwart E, DeRisi JL, Bello PLD, Serio FD, Digiaro M, Dolja VV, Drosten C, Druciarek TZ, Du J, Ebihara H, Elbeaino T, Gergerich RC, Gillis AN, Gonzalez J-PJ, Haenni
A-L, Hepojoki J, Hetzel U, Hồ T, Hóng N, Jain RK, Vuren PJV, Jin Q, Jonson MG, Junglen S, Keller KE, Kemp A, Kipar A, Kondov NO, Koonin EV, Kormelink R, Korzyukov Y, Krupovic M, Lambert AJ, Laney AG, LeBreton M, Lukashevic IS, Marklewitz M, Markotter W, Martelli GP, Martin RR, Mielke-Ehret N, Mühlbach H-P, Navarro B, Ng TFF, Nunes MRT, Palacios G, Pawęska JT, Peters CJ, Plyusnin A, Radoshitzky SR, Romanowski V, Salmenperä P, Salvato MS, Sanfaçon H, Sasaya T, Schmaljohn C, Schneider BS, Shirako Y, Siddell S, Sironen TA, Stenglein MD, Storm N, Sudini H, Tesh RB, Tzanetakis IE, Uppala M, Vapalahti O, Vasilakis N, Walker PJ, Wáng G, Wáng L, Wáng Y, Wèi T, Wiley MR, Wolf YI, Wolfe ND, Wú Z, Xú W, Yang L, Yāng Z, Yeh S-D, Zhāng Y-Z, Zhèng Y, Zhou X, Zhū C, Zirkel F, Kuhn JH (2018) Taxonomy of the family Arenaviridae and the order Bunyavirales: update 2018. Arch Virol 163:2295-2310

20. Maes P, Adkins S, Alkhovsky SV, Avšič-Županc T, Ballinger MJ, Bente DA, Beer M, Bergeron E, Blair CD, Briese T, Buchmeier MJ, Burt FJ, Calisher CH, Charrel RN, Choi IR, Clegg JCS, de la Torre JC, de Lamballerie X, DeRisi JL, Digiaro M, Drebot M, Ebihara H, Elbeaino T, Ergünay K, Fulhorst CF, Garrison AR, Gāo GF, Gonzalez J-PJ, Groschup MH, Günther S, Haenni A-L, Hall RA, Hewson R, Hughes HR, Jain RK, Jonson MG, Junglen S, Klempa B, Klingström J, Kormelink R, Lambert AJ, Langevin SA, Lukashevich IS, Marklewitz M, Martelli GP, Mielke-Ehret N, Mirazimi A, Mühlbach H-P, Naidu R, Nunes MRT, Palacios G, Papa A, Pawęska JT, Peters CJ, Plyusnin A, Radoshitzky SR, Resende RO, Romanowski V, Sall AA, Salvato MS, Sasaya T, Schmaljohn C, Shí X, Shirako Y, Simmonds P, Sironi M, Song J-W, Spengler JR, Stenglein MD, Tesh RB, Turina M, Wèi T, Whitfield AE, Yeh S-D, Zerbini FM, Zhang Y-Z, Zhou X, Kuhn JH (2019) Taxonomy of the order Bunyavirales: second update 2018. Arch Virol 164:927-941

21. Makhsous N, Shean RC, Droppers D, Guan J, Jerome KR, Greninger AL (2017) Genome sequences of three novel bunyaviruses, two novel rhabdoviruses, and one novel nyamivirus from Washington State moths. Genome Announc 5:e01668-e01716

22. Matsuno K, Kajihara M, Nakao R, Nao N, Mori-Kajihara A, Muramatsu M, Qiu Y, Torii S, Igarashi M, Kasajima N, Mizuma K, Yoshii K, Sawa H, Sugimoto C, Takada A, Ebihara H (2018) The unique phylogenetic position of a novel tick-borne phlebovirus ensures an ixodid origin of the genus Phlebovirus. mSphere 3:e00239

23. McMichael L, Persley D, Thomas J (2000) The first record of a serotype IV tospovirus in Australia. Australas Plant Pathol 29:149-150

24. McMullan LK, Folk SM, Kelly AJ, MacNeil A, Goldsmith CS, Metcalfe MG, Batten BC, Albariño CG, Zaki SR, Rollin PE, Nicholson WL, Nichol ST (2012) A new phlebovirus associated with severe febrile illness in Missouri. N Engl J Med 367:834-841

25. Meheretu Y, Cížková D, Těšíková J, Welegerima K, Tomas Z, Kidane D, Girmay K, Schmidt-Chanasit J, Bryja J, Günther S, Bryjová A, Leirs H, Goüy de Bellocq J (2012) High diversity of RNA viruses in rodents, Ethiopia. Emerg Infect Dis 18:2047-2050

26. Navarro B, Minutolo M, De Stradis A, Palmisano F, Alioto D, Di Serio F (2018) The first phlebo-like virus infecting plants: a case study on the adaptation of negative-stranded RNA viruses to new hosts. Mol Plant Pathol 19:1075-1089

27. Rodrigues DSG, Medeiros DBdA, Rodrigues SG, Martins LC, de Lima CPS, de Oliveira LF, de Vasconcelos JM, Da Silva DE, Cardoso JF, da Silva SP, Vianez-Júnior JLdSG, Nunes MRT, Vasconcelos PFdC (2014) Pacui virus, Rio Preto da Eva virus, and Tapirape virus, three distinct viruses within the family Bunyaviridae. Genome Announc 2:e0923

28. Schoonvaere K, De Smet L, Smagghe G, Vierstraete A, Braeckman BP, de Graaf DC (2016) Unbiased RNA shotgun 
metagenomics in social and solitary wild bees detects associations with eukaryote parasites and new viruses. PLoS One 11:e0168456

29. Shchetinin AM, Lvov DK, Deriabin PG, Botikov AG, Gitelman AK, Kuhn JH, Alkhovsky SV (2015) Genetic and phylogenetic characterization of Tataguine and Witwatersrand viruses and other orthobunyaviruses of the Anopheles A, Capim, Guama, Koongol, Mapputta, Tete, and Turlock serogroups. Viruses 7:5987-6008

30. Shen S, Duan X, Wang B, Zhu L, Zhang Y, Zhang J, Wang J, Luo T, Kou C, Liu D, Lv C, Zhang L, Chang C, Su Z, Tang S, Qiao J, Moming A, Wang C, Abudurexiti A, Wang H, Hu Z, Zhang Y, Sun S, Deng F (2018) A novel tick-borne phlebovirus, closely related to severe fever with thrombocytopenia syndrome virus and Heartland virus, is a potential pathogen. Emerg Microbes Infect 7:95

31. Shi M, Lin X-D, Tian J-H, Chen L-J, Chen X, Li C-X, Qin X-C, Li J, Cao J-P, Eden J-S, Buchmann J, Wang W, Xu J, Holmes EC, Zhang Y-Z (2016) Redefining the invertebrate RNA virosphere. Nature 540:539-543

32. Shi M, Neville P, Nicholson J, Eden J-S, Imrie A, Holmes EC (2017) High-resolution metatranscriptomics reveals the ecological dynamics of mosquito-associated RNA viruses in western Australia. J Virol 91:e00680-e00717

33. Shi M, Lin X-D, Chen X, Tian J-H, Chen L-J, Li K, Wang W, Eden J-S, Shen J-J, Liu L, Holmes EC, Zhang Y-Z (2018) The evolutionary history of vertebrate RNA viruses. Nature 556:197-202

34. Song J-W, Gu SH, Bennett SN, Arai S, Puorger M, Hilbe M, Yanagihara R (2007) Seewis virus, a genetically distinct hantavirus in the Eurasian common shrew (Sorex araneus). Virol J 4:114

35. Tokarz R, Sameroff S, Tagliafierro T, Jain K, Williams SH, Cucura DM, Rochlin I, Monzon J, Carpi G, Tufts D, Diuk-Wasser M, Brinkerhoff J, Lipkin WI (2018) Identification of novel viruses in Amblyomma americanum, Dermacentor variabilis, and Ixodes scapularis ticks. mSphere 3:e00614-e00617

36. Zhou J, Kantartzi SK, Wen R-H, Newman M, Hajimorad MR, Rupe JC, Tzanetakis IE (2011) Molecular characterization of a new tospovirus infecting soybean. Virus Genes 43:289-295

Publisher's Note Springer Nature remains neutral with regard to jurisdictional claims in published maps and institutional affiliations.

\title{
Affiliations
}

\begin{abstract}
Abulikemu Abudurexiti ${ }^{1}$. Scott Adkins ${ }^{2}$ - Daniela Alioto ${ }^{3}$ - Sergey V. Alkhovsky ${ }^{4}$ (D) Tatjana Avšič-Županc ${ }^{5}$.

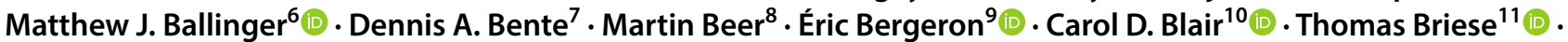
Michael J. Buchmeier ${ }^{12}$ - Felicity J. Burt ${ }^{13}$ (D) . Charles H. Calisher ${ }^{10}$. Chénchén Cháng ${ }^{14} \cdot$ Rémi N. Charrel $^{15}$ (1) II Ryong Choi ${ }^{16}$. J. Christopher S. Clegg ${ }^{17}$. Juan Carlos de la Torre ${ }^{18}\left({ }^{\circ} \cdot\right.$ Xavier de Lamballerie $^{15}$. Fēi Dèng ${ }^{19}$ (i) Francesco Di Serio ${ }^{20}$ (1) Michele Digiaro ${ }^{21}$ - Michael A. Drebot ${ }^{22} \cdot$ Xiǎoméi Duàn $^{14} \cdot$ Hideki Ebihara $^{23}$ (1) . Toufic Elbeaino ${ }^{21} \cdot$ Koray Ergünay ${ }^{24}\left({ }^{10}\right.$. Charles F. Fulhorst ${ }^{7} \cdot$ Aura R. Garrison ${ }^{25}$. George Fú Gāo ${ }^{26}$.

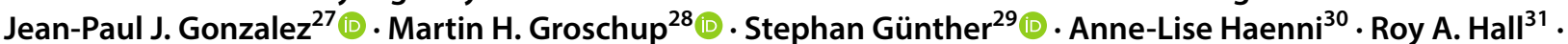

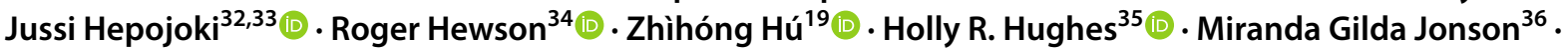

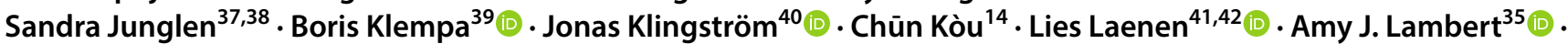
Stanley A. Langevin ${ }^{43}$. Dan Liu ${ }^{44}$. Igor S. Lukashevich ${ }^{45}$ (1) Tão Luò $^{1}$. Chuánwèi Lü̆ ${ }^{19}$. Piet Maes ${ }^{41}(1)$.

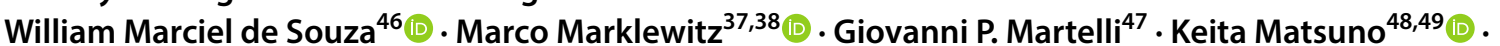
Nicole Mielke-Ehret ${ }^{50} \cdot$ Maria Minutolo $^{3}$ - Ali Mirazimi ${ }^{51}$ - Abulimiti Moming ${ }^{14}$. Hans-Peter Mühlbach ${ }^{50}$. Rayapati Naidu ${ }^{52} \cdot$ Beatriz Navarro ${ }^{20}$ (1) Márcio Roberto Teixeira Nunes ${ }^{53}$ (D) . Gustavo Palacios ${ }^{25}$ (D) . Anna Papa ${ }^{54}$. Alex Pauvolid-Corrêa ${ }^{55}$. Janusz T. Pawęska ${ }^{56,57}$ (1) Jié Qiáo ${ }^{19}$. Sheli R. Radoshitzky ${ }^{25}$ (1). Renato O. Resende ${ }^{58}$ (Díctor Romanowski ${ }^{59} \cdot$ Amadou Alpha Sall ${ }^{60} \cdot$ Maria S. Salvato ${ }^{61}$ (1) $\cdot$ Takahide Sasaya $^{62}$ (1) Shū Shěn ${ }^{19}$ (1) Xiǎohóng Shí6 ${ }^{63}$ - Yukio Shirako ${ }^{64} \cdot$ Peter Simmonds $^{65}$ (i) $\cdot$ Manuela Sironi $^{66}$ (1)

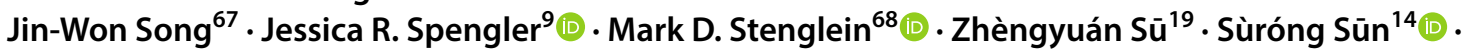
Shuāng Táng ${ }^{19}$. Massimo Turina ${ }^{69}$ (1) B Bó Wáng ${ }^{19}$. Chéng Wáng ${ }^{1} \cdot$ Huálín Wáng ${ }^{19}$. Jūn Wáng ${ }^{19}$. Tàiyún Wèi $^{70} \cdot$ Anna E. Whitfield ${ }^{71}$ (1) $\cdot$ F. Murilo Zerbini ${ }^{72}$. Jìngyuàn Zhāng ${ }^{14}$. Lěi Zhāng ${ }^{19}$. Yànfāng Zhāng ${ }^{19}$. Yong-Zhen Zhang ${ }^{73,74}$. Yújiāng Zhāng ${ }^{1} \cdot$ Xueping Zhou $^{75}$ • Lìyǐng Zhü ${ }^{19}$ • Jens H. Kuhn ${ }^{76}$
\end{abstract}

Jens H. Kuhn

kuhnjens@mail.nih.gov

1 Center for Disease Control and Prevention of Xinjiang Uygur Autonomous Region, Ürümqi, China

2 United States Department of Agriculture, Agricultural Research Service, US Horticultural Research Laboratory, Fort Pierce, FL, USA

3 Dipartimento di Agraria, Università degli Studi di Napoli Federico II, Portici, Italy

4 D. I. Ivanovsky Institute of Virology, N. F. Gamaleya Federal Research Center for Epidemiology and Microbiology, Ministry of Health of the Russian Federation, Moscow, Russia
5 University of Ljubljana, Ljubljana Faculty of Medicine, Ljubljana, Slovenia

6 Department of Biological Sciences, Mississippi State University, Mississippi State, MS, USA

7 University of Texas Medical Branch, Galveston, TX, USA

8 Institute of Diagnostic Virology, Friedrich-Loeffler-Institut, Greifswald-Insel Riems, Germany

9 Viral Special Pathogens Branch, Division of High-Consequence Pathogens and Pathology, Centers for Disease Control and Prevention, Atlanta, GA, USA

10 Colorado State University, Fort Collins, CO, USA 
11 Center for Infection and Immunity, and Department of Epidemiology, Mailman School of Public Health, Columbia University, New York, NY, USA

12 Department of Molecular Biology and Biochemistry, University of California, Irvine, CA, USA

13 Division of Virology, National Health Laboratory Service and Division of Virology, University of the Free State, Bloemfontein, Republic of South Africa

14 Xinjiang Key Laboratory of Biological Resources and Genetic Engineering, College of Life Science and Technology, Xinjiang University, Ürümqi, China

15 Unité des Virus Emergents (Aix-Marseille Univ-IRD 190-Inserm 1207-IHU Méditerranée Infection), Marseille, France

16 Plant Breeding Genetics and Biotechnology Division and International Rice Research Institute, Los Baños, Philippines

17 Les Mandinaux, Le Grand Madieu, France

18 Department of Immunology and Microbiology IMM-6, The Scripps Research Institute, La Jolla, CA, USA

19 State Key Laboratory of Virology, Wuhan Institute of Virology, Chinese Academy of Sciences, Wuhan, China

20 Istituto per la Protezione Sostenibile delle Piante, Consiglio Nazionale delle Ricerche, Bari, Italy

21 Istituto Agronomico Mediterraneo di Bari, Valenzano, Italy

22 Zoonotic Diseases and Special Pathogens, National Microbiology Laboratory, Public Health Agency of Canada, Winnipeg, MB, Canada

23 Department of Molecular Medicine, Mayo Clinic, Rochester, MN, USA

24 Virology Unit, Department of Medical Microbiology, Hacettepe University, Faculty of Medicine, Ankara, Turkey

25 United States Army Medical Research Institute of Infectious Diseases, Fort Detrick, Frederick, MD, USA

26 National Institute for Viral Disease Control and Prevention, Chinese Center for Disease Control and Prevention, Beijing, China

27 Center of Excellence for Emerging and Zoonotic Animal Disease, Kansas State University, Manhattan, KS, USA

28 Institute of Novel and Emerging Infectious Diseases, Friedrich-Loeffler-Institut, Greifswald-Insel Riems, Germany

29 Department of Virology, Bernhard-Nocht Institute for Tropical Medicine, WHO Collaborating Centre for Arboviruses and Hemorrhagic Fever Reference and Research, Hamburg, Germany

30 Institut Jacques Monod, CNRS-Université Paris-Diderot, Paris, France

31 Australian Infectious Diseases Research Centre, School of Chemistry and Molecular Biosciences, The University of Queensland, Brisbane, Australia

32 Department of Virology, University of Helsinki, Faculty of Medicine, Medicum, Helsinki, Finland

33 Institute of Veterinary Pathology, Vetsuisse Faculty, University of Zurich, Zurich, Switzerland
34 Public Health England, Porton Down, Wiltshire, Salisbury, UK

35 Centers for Disease Control and Prevention, Division of Vector-Borne Diseases, Fort Collins, CO, USA

36 Department of Agricultural Biotechnology, Center for Fungal Pathogenesis, College of Agriculture and Life Sciences, Seoul National University, Seoul, Korea

37 Charité-Universitätsmedizin Berlin, Corporate Member of Free University Berlin, Humboldt-University Berlin, and Berlin Institute of Health, Berlin, Germany

38 German Centre for Infection Research, Berlin, Germany

39 Biomedical Research Center, Slovak Academy of Sciences, Bratislava, Slovakia

40 Center for Infectious Medicine, Department of Medicine Huddinge, Karolinska Institutet, Karolinska University Hospital, Stockholm, Sweden

41 KU Leuven, Rega Institute, Zoonotic Infectious Diseases Unit, Leuven, Belgium

42 Department of Laboratory Medicine, University Hospitals Leuven, Leuven, Belgium

43 Department of Microbiology, University of Washington, Washington, USA

44 School of Medicine, Wuhan University of Science and Technology, Wuhan, China

45 Department of Pharmacology and Toxicology, School of Medicine, and the Center for Predictive Medicine for Biodefense and Emerging Infectious Diseases, University of Louisville, Louisville, KY, USA

46 Virology Research Center, School of Medicine of Ribeirão Preto, University of São Paulo, Ribeirão Preto, São Paulo, Brazil

47 Department of Plant, Soil, and Food Sciences, University "Aldo Moro", Bari, Italy

48 Laboratory of Microbiology, Faculty of Veterinary Medicine, Hokkaido University, Sapporo, Japan

49 Global Institution for Collaborative Research and Education (GI-CoRE), Hokkaido University, Sapporo, Japan

50 Biocentre Klein Flottbek, University of Hamburg, Hamburg, Germany

51 Folkhälsomyndigheten, Stockholm, Sweden

52 Department of Plant Pathology, Irrigated Agricultural Research and Extension Center, Washington State University, Prosser, WA, USA

53 Evandro Chagas Institute, Ministry of Health, Pará, Brazil

54 National Reference Centre for Arboviruses and Haemorrhagic Fever Viruses, Department of Microbiology, Medical School, Aristotle University of Thessaloniki, Thessaloníki, Greece

55 Flavivirus Laboratory, Oswaldo Cruz Foundation, Ministry of Health, Rio de Janeiro, Brazil

56 Centre for Emerging Zoonotic and Parasitic Diseases, National Institute for Communicable Diseases, National Health Laboratory Service, Sandringham, South Africa 
57 Centre for Viral Zoonoses, Department of Medical Virology, Faculty of Health Sciences, University of Pretoria, Pretoria, South Africa

58 Departamento de Biologia Celular, Universidade de Brasília, Brasília, Brazil

59 Instituto de Biotecnología y Biología Molecular, Centro Científico Tecnológico-La Plata, Consejo Nacional de Investigaciones Científicas y Técnicas-Universidad Nacional de La Plata, La Plata, Argentina

60 Institut Pasteur de Dakar, Dakar, Senegal

61 Institute of Human Virology, University of Maryland School of Medicine, Baltimore, MD, USA

62 Division of Argo-Environment Research, Western-region Agricultural Research Center, National Agriculture and Food Food Research Organization, Fukuyama, Japan

63 MRC-University of Glasgow Centre for Virus Research, Glasgow, Scotland, UK

64 Asian Center for Bioresources and Environmental Sciences, University of Tokyo, Tokyo, Japan

65 Nuffield Department of Medicine, University of Oxford, Oxford, UK

66 Bioinformatics, Scientific Institute IRCCS “E. Medea”, Bosisio Parini, Italy

67 Department of Microbiology, College of Medicine, Korea University, Seoul, Republic of Korea
68

Department of Microbiology, Immunology, and Pathology, Colorado State University, Fort Collins, CO, USA

69 Institute for Sustainable Plant Protection, National Research Council, Turin, Italy

70 Fujian Province Key Laboratory of Plant Virology, Institute of Plant Virology, Fujian Agriculture and Forestry University, Fuzhou, Fujian, China

71 Department of Entomology and Plant Pathology, North Carolina State University, Raleigh, NC, USA

72 Departamento de Fitopatologia/Instituto de Biotecnologia Aplicada à Agropecuária, Universidade Federal de Viçosa, Viçosa, Minas Gerais, Brazil

73 National Institute for Communicable Disease Control and Prevention, Chinese Center for Disease Control and Prevention, Changping, Beijing, China

74 Shanghai Public Health Clinical Center and Institutes of Biomedical Sciences, Fudan University, Shanghai, China

75 State Key Laboratory for Biology of Plant Diseases and Insect Pests, Institute of Plant Protection, Chinese Academy of Agricultural Sciences, Beijing, China

76 Integrated Research Facility at Fort Detrick (IRF-Frederick), Division of Clinical Research (DCR), National Institute of Allergy and Infectious Diseases (NIAID), National Institutes of Health (NIH), B-8200 Research Plaza, Fort Detrick, Frederick, MD 21702, USA 